\title{
PREVALENCE OF INTESTINAL HELMINTHIC INFECTIONS AMONG UNDERFIVES AND KNOWLEDGE ON HELMINTHIASES AMONG MOTHERS OF THE UNDERFIVES IN DAR ES SALAAM, TANZANIA.
}

\author{
K.D. Mwambete and N Kalison
}

\begin{abstract}
Objective: To assess the prevalence of intestinal helminthic infections (IHIs) among underfives attending peadiatric clinics at Amana and Mwananyamala Hospitals in Dar es Salaam (Tanzania) and assess the knowledge on IHIs among mothers of the underfives.

Methods: A cross sectional study with the use of 4537 checklists of clinical histories dated 2003-2004 and face to face interview with 100 mothers of underfives infected with helminths was conducted in Dar es Salaam, Tanzania. A simple convenient sampling method was used to select two hospitals whereby 50 mothers from each hospital participated. Semi-structured questionnaire was used for data collection, which focused on knowledge of IHIs, control measures, treatment and diagnosis. Results: Prevalence of IHIs at Mwananyamala hospital was $\mathbf{4 6 . 5 4 \%}$ for Ascaris, $37.48 \%$ for hookworm and $\mathbf{1 5 . 9 8 \%}$ for Trichuris infections. For Amana hospital the prevalence was $\mathbf{4 0 . 5 0 \%}$ for Ascaris, $\mathbf{4 1 . 8 3} \%$ for hookworm and $\mathbf{1 7 . 6 8 \%}$ for Trichuris infections. The overall prevalence of IHIs in both hospitals for 2003-2004 was comparable in male (48\%) and female $(52 \%)$ underfives $(p<0.05)$. Results also revealed that $66 \%$ of mothers had no knowledge on IHIs prevention, and $40 \%$ of the interviewees were incapable of naming any anthelminthic. About $82 \%$ of the respondents were unable to describe even a single helminth, and a significant number of them $(92 \%)$ did not routinely carry out deworming process $(p<0.001)$. Results also revealed that $80 \%$ of the underfives were accidentally diagnosed with IHIs while visiting clinics for other health problems, and $10 \%$ of the underfives were undiagnosed until they started passing worms in faeces or vomits.

Conclusions: Ignorance on possible preventive measures and lack of knowledge on IHIs attributed to poor visits to clinics among the studied subjects and to high prevalence of IHIs in the two studied districts. IHI is still a public health problem in Dare es Salaam that seems to be neglected.
\end{abstract}

Key words: prevalence, helminths, knowledge, underfives, infection

\section{Introduction}

Intestinal helminthiasis or intestinal helminthic infections (IHIs) is a public health problem in Tanzania and in most of the developing tropical countries $(1,2,3)$. The most common intestinal helminths that attribute to the majority of parasitic infections throughout the world are Ascaris lumbricoides, Trichuris trichiura and hookworms (Ancylostoma duodenale and Necator americanus). They affect more than one billion people particularly children in developing countries (4), and the homeless. IHIs are usually asymptomatic but serious infections may cause symptoms ranging from abdominal discomfort to severe pain, anorexia, nausea, diarrhoea and pruritus. Rectal prolapse occurs in nearly $4 \%$ of children with trichuriasis (5) while bowel obstruction occurs in about $35 \%$ of all children with ascariasis in tropical countries (1). Hookworm infection is associated with anaemia, stunted physical growth and sometimes death may occur (6-8).

IHI can be acquired through ingesting food contaminated with the infective stage of Ascaris lumbricoides and T. trichiura. Infection by hookworm is through skin penetration for $N$. americanus while $A$. duodenale infects human beings equally successfully by percutaneous, oral, transmammary and probably transplacental route (9). The severity of most infections is related to worm burden $(3,10-12)$. This calls for the need to quantify the impact of IHIs on human health and to understand the mechanisms behind their adverse effects (13).

Correspondence to: KD Mwambete, Muhimbili University College of Health Sciences. P. O. Box 65013, Dar es Salaam, Tanzania. E-mail:dmwambete $a$ muchs.ac.tz Department of Pharmaceutical Microbiology, School of Pharmacy
In Tanzania, the socio-economic conditions of the majority of the people is poor, therefore the problem of IHIs cannot be escaped. Many of Tanzanians migrate from rural areas to urban areas to find better lives. The consequences of high population in one area is shortage of social facilities and services like water, overcrowding, inadequate latrine facilities in most areas, which contribute to poor hygienic conditions and increase of parasitic intestinal helminthiases (14), particularly among underfives. This is the first study, which relates prevalence of IHIs and knowledge of the underfives' mothers on specific aspects related with helminthiasis. The study aimed at identifying the prevalence of these IHIs and to evaluate the mothers' know-how on types of IHIs, symptoms, and general care of the underfives with IHI problems.

\section{Methodology}

\section{Study design}

This was a cross sectional-based study with the use of checklists of clinical histories. The target population was all mothers having children under age of 5 years, who were infected with helminths and attending outpatient underfive clinics at Amana (Ilala district) and Mwananyamala (Kinondoni district) hospitals. The Swahili version of the semi-structured questionnaires were used to interview the mothers in order to assess their awareness and knowledge on helminthiases.

\section{Sample size}

A total of 100 mothers whose underfive children were infected with intestinal helminths and who attended clinics at the above mentioned two district hospitals were invited 
to participate in the survey. Before participation, consenting mothers were informed on the purpose of the study and had liberty to refuse participation. The collected data were complemented with a retrospective study of clinical histories for the year 2003-2004 at the respective hospitals.

\section{Statistical analysis}

The data were analyzed using the statistical package for social science (SPSS/PC+) version 10. The Chi-squared $\left(\chi^{2}\right)$ test was used in statistical testing and results were significant if $P \leq 0.05$.

\section{Results}

\section{Knowledge of the mothers on helminthiases}

A total of 100 questionnaires were used for data collection by interviewing mothers with underfives whether they were aware of IHIs or not. Most of the interviewed mothers of the underfives $(82 \%)$ were unaware of the intestinal helminths, and $40 \%$ of them could not mention even a single anthelminthic (Table 1). It was also found that majority of the respondents were primary school leavers $(62 \%)$. Symptoms associated with IHIs that most of the respondents knew were loss of appetite, abdominal pain, weight loss and coughing. Half of the mothers (50) visited the clinics only once per year. Over $83 \%$ of the patients (underfives) were discovered to be harboring helminths by both laboratory investigation and by personal observation of symptoms (Table 1). The commonest symptoms described by the respondents $(20 \%)$ through which their underfives were discovered to be harbouring helminths were rashes, vomiting and passing worms per rectum (data not shown).

Table 1. Responses given to different questions asked to the 100 mothers of underfives

\begin{tabular}{lcccr}
\hline Questions & & & & Responses (\%) \\
\hline Types of helminths & $\begin{array}{c}\text { Hookworm } \\
(8)\end{array}$ & Ascaris (10) & & $\begin{array}{r}\text { Don't know } \\
(82)\end{array}$ \\
$\begin{array}{l}\text { Education level } \\
\text { No. of clinic visits } \\
\text { Discovery of IHIs }\end{array}$ & $\begin{array}{c}\text { Primary (62) } \\
\mathbf{1}(50) \\
\text { Lab. } \\
\text { observations } \\
(10)\end{array}$ & $\begin{array}{c}\text { Secondary (23) } \\
2(15) \\
\text { Personal } \\
\text { bservations (10) }\end{array}$ & $\begin{array}{c}\text { Tertiary (5) } \\
\mathbf{3 ( 1 0 )} \\
\text { Both (80) }\end{array}$ & $\begin{array}{c}\text { None (10) } \\
\geq 4(25) \\
-\end{array}$ \\
$\begin{array}{c}\text { ABZ (35) } \\
\text { Drugs against IHIs }\end{array}$ & LVL (5) & MBZ (20) & $\begin{array}{c}\text { Don't know } \\
(40)\end{array}$ \\
Vulnerability & Females (25) & Males (5) & Equal (10) & $\begin{array}{c}\text { Don't know } \\
(60)\end{array}$ \\
No. of children & $1(24)$ & $2(27)$ & $3(10)$ & $\geq 4(16)$ \\
\hline
\end{tabular}

${ }^{\text {a }}$ the same figure is expressed in numbers of the studied case as well as in percentages

When asked about the drugs that were used to treat IHIs for their children, $40 \%$ of mothers did not know the drugs. However, albendazole (ABZ) was the most frequently mentioned anthelminthic by $35 \%$ of the respondents, followed by mebendazole-MBZ $(20 \%)$ and levamisole-LVL $(5 \%)$, which were also mentioned by a few interviewees who knew the drugs, as depicted in Table 1. With respect to vulnerability to IHIs between male and female underfives, most of the respondents $(60 \%)$ could not tell who were more vulnerable (Table1). The majority of the mothers had more than one child (76\%) implying that they had enough experience on the general child care.

It was also found that majority of the underfives $(80 \%)$ were diagnosed to be infected with intestinal helminths accidentally while attending clinic for other health problems such as fever, coughing and malaria (Table 2). Results also show that $66 \%$ of the mothers did not know any means of preventing IHIs as shown in Table 2. With regard to whether they had to change drugs, $80 \%$ of the respondents said they did not change the drugs. Of the $20 \%$ who had ever changed drugs, attributed the change to the drug resistance. The study found that out of 100 interviewed mothers, $60 \%$ of them had male underfive children (data not shown). The study also revealed that a significant number of the mothers (92\%) hardly carried out periodic deworming of the underfives compared to $8 \%$ who did $(p<0.001)$. In addition to that, when the interviewees were asked whether parents were the sources of IHIs, 75\% responded affirmatively (Table 2).

Table 2: Responses given by 100 mothers of underfives on the various investigated aspects

\begin{tabular}{|c|c|c|c|}
\hline \multirow[b]{2}{*}{ Investigated aspects } & \multicolumn{3}{|c|}{ Responses (\%) } \\
\hline & Yes & No & $\begin{array}{l}\text { Don't } \\
\text { know }\end{array}$ \\
\hline $\begin{array}{l}\text { Suffering from other diseases than } \\
\text { IHIs }\end{array}$ & 80 & 15 & 5 \\
\hline Existence of preventive measures & 34 & 21 & 45 \\
\hline Change of drugs & 20 & 80 & - \\
\hline Does periodic deworming & 8 & 92 & - \\
\hline Parents are source of IHIs & 75 & 15 & 10 \\
\hline
\end{tabular}

${ }^{a}$ the same figure is expressed in numbers of the studied case as well as in percentages

\section{Prevalence of IHIs}

A total of 4537 cases from both district hospitals namely Amana hospital (2144) and Mwananyamala hospital (2393) were retrospectively analyzed from the checklist of documents dated 2003-2004. Out of 4537 underfives, $2183(48.1 \%)$ were males and $2354(51.9 \%)$ were females (Table 3-4). In the two years, it was found that more females (1131) against 1045 males, and 1228 females against 1133 males were infected in 2003 and 2004 respectively, though the differences were not statistically significant $(p<0.05)$. Prevalence of IHIs at Amana hospital (Ilala district) in both years was as follows: for Ascaris infection 40.5\% (882) and out of those 514 were males and 368 were females. The prevalence for hookworm infection was $41.8 \%$ (911), out of those 524 were males and 387 were females. The prevalence of trichuriasis was $17.7 \%$ (385) of whom 194 were male and 191 female underfives (Table 4). Prevalence of helminthiases at Mwananyamala hospital (Kinondoni district) for the two years (2003-2004) is also summarized in Table 4. The prevalence of Ascariasis was 46.5\% (1098) out of those 438 were males and 660 were females. 
Prevalence of hookworm infection was $37.5 \%$ (884) of those 361 were males and 523 were females. For Trichuris infection was $16.0 \%$ (377) which comprised of 152 males and 225 female underfives.

Table 3. Prevalence of helminthiases among underfives in the year 2003-2004 grouped per sex of the underfives

\begin{tabular}{llcll}
\hline & \multicolumn{2}{c}{$\mathbf{2 0 0 3} \mathbf{( \% )}$} & $\mathbf{2 0 0 4}(\mathbf{\%})$ \\
\cline { 2 - 5 } Helminthiasis & Male & Female & Male & Female \\
\hline Ascariasis & $529(24.67)$ & $509(23.74)$ & $441(18.43)$ & $499(20.85)$ \\
Hookworm & $352(16.42)$ & $425(19.82)$ & $538(22.48)$ & $480(20.06)$ \\
Trichuriasis & $164(7.65)$ & $197(9.18)$ & $154(6.43)$ & $249(10.40)$ \\
\hline
\end{tabular}

Table 4: Prevalence of IHIs among underfives in the two studied centers

\begin{tabular}{llll}
\hline \multirow{2}{*}{ Helminthiasis } & Child sex & \multicolumn{2}{l}{ Health centre } \\
\cline { 3 - 4 } & & $\begin{array}{l}\text { Mwananyamala } \\
(\%)\end{array}$ & nana (\%) \\
\hline Ascariasis & Female & $660(27.98)$ & $368(16.90)$ \\
& Male & $438(18.56)$ & $514(23.60)$ \\
Hookworm & Female & $523(22.18)$ & $387(17.77)$ \\
& Male & $361(15.30)$ & $524(24.06)$ \\
Trichuriasis & Female & $225(9.54)$ & $191(8.77)$ \\
& Male & $152(6.44)$ & $194(8.91)$ \\
\hline
\end{tabular}

The overall prevalence of IHIs was $43.6 \%$ (1978) for Ascariasis, 39.6\% (1705) for hookworm infections and $16.8 \%$ (764) for Trichuriasis. Prevalence of IHIs was also assessed with respect to age and sex of the underfives for both hospitals. The findings revealed that Trichuriasis was more predominant in underfives between the age of 2.5-3 years, while those older than 3.5 years were found to be infected with more than one helminth (mixed infections) (Table 5). Summary on number of the underfives, and types of IHIs in relation to the drugs used against the infections is depicted in Table 6 . The study shows that out of 4537 underfives, ABZ was used by $74.8 \%$ (3392) that is it was the most frequently used anthelminthic followed by MBZ (18.9\%) and LVL (6.2\%), whilst the least used $(0.1 \%)$ was praziquantel (PZQ).

Table 5: Analysis of IHIs with respect to age of the underfives and their treatment

\begin{tabular}{lll}
\hline Helminthiasis & $\begin{array}{l}\text { Child age } \\
\text { (years) }\end{array}$ & Treatment \\
\hline Hookworm & $\leq 2.0$ & ABZ, MBZ, LVL, PZQ \\
Ascariasis & $2.0-2.5$ & ABZ, MBZ, LVL \\
Trichuriasis & $2.5-3.0$ & ABZ, MBZ, LVL, PZQ \\
Mixed infections & $3.5-5.0$ & ABZ, MBZ, LVL, PZQ \\
& & \\
\hline
\end{tabular}

Table 6: Prevalence of IHIs among underfives with respect to drugs used against the IHIs

\begin{tabular}{|c|c|c|c|c|c|}
\hline \multirow[t]{2}{*}{ Child sex } & \multirow[t]{2}{*}{ Diagnossis } & \multicolumn{4}{|c|}{ Treatment (\%) } \\
\hline & & $\overline{A B Z}$ & MBZ & LVL & PZQ \\
\hline \multirow[t]{3}{*}{ Male } & Ascariasis & 679 (14.97) & $87(1.92)$ & $72(1.59)$ & $0(0.00)$ \\
\hline & Hookworm & $611(13.47)$ & 71 (1.56) & 49 (1.08) & $2(0.04)$ \\
\hline & Trichuriasis & $119(2.62)$ & 212 (4.67) & $11(0.24)$ & $2(0.04)$ \\
\hline \multirow[t]{3}{*}{ Female } & Ascariasis & 972 (21.42) & $93(2.05)$ & 75 (1.65) & $0(0.00)$ \\
\hline & Hookworm & $929(20.48)$ & 69 (1.52) & 63 (1.39) & $1(0.02)$ \\
\hline & Trichuriasis & $82(1.81)$ & $328(7.23)$ & $10(0.22)$ & $0(0.00)$ \\
\hline
\end{tabular}

\section{Discussion}

Results from the direct interview with the mothers having underfives infected with IHIs revealed that most of the respondents lacked adequate knowledge on IHIs. This finding is similar to previous reports from other helminthic infections $(2,15,16)$. Majority of the mothers whose children were infected with intestinal helminths had primary school education level, and this might be one of factors that attributed to inability to associate IHIs with the symptoms or being unaware of the preventive measures. The above observation is not uncommon as similar observations have been reported in other countries $(2,12)$. Also the observed poor attendance to clinics could be due to illiteracy on IHIs which in turn might have greatly attributed to the lack of knowledge on anthelminthics and failure to name even a single drug prescribed by doctors or used for treatment of IHIs. This is evidenced by the fact that $50 \%$ of the respondents confessed that they usually took their children to clinics only once per year. Majority of the mothers $(76 \%)$ had more than one child (Table 1); this could imply that lack of knowledge on IHIs might not necessarily be linked with inexperience on the general child care. Besides the fact that most of the mothers $(82 \%)$ did not change anthelminthics, a few had done because of what was described as drug resistance. This needs further studies to determine whether there is anthelminthic resistance in human helminths in Tanzania; taking into account that other authors have also reported similar findings $(17,18)$.

Moreover, results from the retrospective study show that there is no significant differences in prevalence of IHIs between female and male underfives. This signifies that there is no correlation between sex and IHIs. Therefore, this study indicates that both female and male underfives were exposed to the same factors. During the interview with the underfives' mothers, $80 \%$ of them agreed that they could be the source of IHIs, as a consequence of poor personal hygienic conditions and lack of appropriate sanitary facilities. Furthermore, results on the prevalence of IHIs for the two years (2003-2004) showed that Ascaris infection was the most prominent (43.6\%). This finding is consistent with other published reports (19) which found that Ascaris infection was the most predominant. Nevertheless, our results differ from those were previously obtained in Dar es Salaam where it was found that hookworm infection was the most prevalent infection (3). The differences in prevalences might be due to socioeconomic changes that have taken place for more than two decades ago (1991) when the study was conducted up to the present time.

In conclusion, it was observed that IHIs is a public health problem among underfives in the two surveyed district hospitals. Lack of knowledge on helminths and IHIs among the underfives' mothers may be among several causes that greatly contribute to ignorance and inability to effectively control IHIs. The study revealed that the prevalence of IHIs was high in the studied areas. This calls 
for a much greater effort and attention from the relevant authorities to design appropriate IHIs preventive and control strategies. The fact that majority of mothers whose children were infected with intestinal helminths had primary school education level; this raises concern to provide them with health education on mode of transmission, types of IHIs, treatment as well as on preventive and control measures. Finally, we suggest that the government, through the Tanzanian Ministry of Health, should think of providing anthelminthics free of charge to all infected underfives as well as for prophylactic purposes.

\section{Acknowledgement}

This study received financial support from the Female Undergraduate Scholarship Programme (FUSP) that is Carnegie sponsorship.

\section{References}

1. Pawlowski $Z$. Intestinal helminthiases and human health: recent advances and future needs. Int $J$ Parasitol 1987 Feb; 17(1): 159-67. Review

2. Johnston K. Courtright P. and Burnham G. Knowledge and attitudes toward onchocerciasis in the Thyolo highlands of Malawi. Trop Med Parasitol 1994 Dec; 45(4):341-3.

3. Killewo JZJ, Caincross SJ, Mahikwano LF and Van Asten H. Pattern of Hookworm and Ascaris infection in Dare es Salaam. Acta Tropica 1991; 48:247249.

4. Hadju V, Abadi K, Stephenson LS, Noor NN, Mohammed HO, Bowman DD. Intestinal helminthiasis, nutritional status, and their relationship; a crosssectional study in urban slum school children in Indonesia. Southeast Asian J Trop Med Public Health 1995 Dec; 26(4):719-29.

5. Bundy DAP and Cooper ES. Trichuris and Trichuriasis in humans. Adv Parasitol 1989; 28:107-173

6. Pawlowski, Z. Implication of parasitic nutrition interactions from a World perspective. Fed Proc 1984 Feb; 43(2):256-260
7. Bundy DAP. The Global burden of intestinal nematodes: Transactions of the Royal Soc Trop Med Hyg 1994; 88(3): 257-368

8. Guyyat HL, Brooker S, Kihamia CM, Hall A and Bundy DAP. Evaluation of efficacy of school-based anthelminthic treatment against anaemia in children in the United Republic of Tanzania. Bull. WHO. Vol. 79, No.8 Geneva 2001.

9. Manson-Bahr PE. Manson's Tropical Disease. $19^{\text {th }}$ Edition London: Bailliere Manson-Bahr
Tindall; 1987.

10. Stephenson, LS. Impact of helminthic infections on human nutrition. Schistosomes and Soil Transmitted Helminths. New York; Taylor and Francis; 1987.

11. Lwambo NJS, Bundy DAP and Medley GFH. Anew approach to morbidity assessment in hookworm endemic communities. Epid Infect 1992; 469-481

12. WHO, Guidelines for the evaluation of Soil-transmitted helminsthiasis and schistosomiasis at community level, WHO/CTD/SIP/98.1 WHO, Geneva; 1998.

13. Barnett ED, Pelton, SI, Vinci RT et al. Reported use of antimicrobial agents in children attending a pediatric emergency department. Peadiatr Infect Dis J 1991 Dec; 10 (12):949-50.

14. Mwaluko, GM, Lukmanji $Z$, and Kasale HAS. Urbanization and Health. In Mwaluko G, Kilama W, Muru M et al. eds. Health and Diseases in Tanzania. Harper Collins Academic; 1991.

15. Ovuga EB. Social and psychological aspects of onchocercal skin disease in Nebbi district, Uganda. East Afr Med J 1995 Jul; 72(7):449-53.

16. Edungbola LD. Cutaneous myiasis due to tumbu-fly, Cordylobia anthropophaga in Ilorin, Kwara State, Nigeria. Acta Tropica 1982; 39: 355-362.

17. Geerts $S$ and Gryseels B. Anthelmintic resistance in human helminths: a review. Trop Med Int Health, 2001; 6(11):915-21.

18. Cioli D. Praziquantel: is there real resistance and are there alternatives? Curr Opinion Infect Dis 2000; 13:1-5.

19. Latham MC. The dermatosis of kwashiorkor in young children. Semin dermatol 1991 Dec; 10(4): 270-272. Review 